\title{
Video Article \\ Introducing Shear Stress in the Study of Bacterial Adhesion
}

\author{
Magali Soyer ${ }^{1}$, Guillaume Duménil ${ }^{1}$ \\ ${ }^{1}$ Blood vessels as a target for infection, Paris center for cardiovascular research, INSERM U970
}

Correspondence to: Guillaume Duménil at guillaume.dumenil@inserm.fr

URL: https://www.jove.com/video/3241

DOI: doi:10.3791/3241

Keywords: Immunology, Issue 55, microbiology, blood vessel, shear stress, blood flow, adhesion, infectious disease, meningitis, brain, septicemia, sepsis

Date Published: 9/2/2011

Citation: Soyer, M., Duménil, G. Introducing Shear Stress in the Study of Bacterial Adhesion. J. Vis. Exp. (55), e3241, doi:10.3791/3241 (2011).

\section{Abstract}

During bacterial infections a sequence of interactions occur between the pathogen and its host. Bacterial adhesion to the host cell surface is often the initial and determining step of the pathogenesis. Although experimentally adhesion is mostly studied in static conditions adhesion actually takes place in the presence of flowing liquid. First encounters between bacteria and their host often occur at the mucosal level, mouth, lung, gut, eye, etc. where mucus flows along the surface of epithelial cells. Later in infection, pathogens occasionally access the blood circulation causing life-threatening illnesses such as septicemia, sepsis and meningitis. A defining feature of these infections is the ability of these pathogens to interact with endothelial cells in presence of circulating blood. The presence of flowing liquid, mucus or blood for instance, determines adhesion because it generates a mechanical force on the pathogen. To characterize the effect of flowing liquid one usually refers to the notion of shear stress, which is the tangential force exerted per unit area by a fluid moving near a stationary wall, expressed in dynes/ $\mathrm{cm}^{2}$. Intensities of shear stress vary widely according to the different vessels type, size, organ, location etc. $\left(0-100 \mathrm{dynes} / \mathrm{cm}^{2}\right)$. Circulation in capillaries can reach very low shear stress values and even temporarily stop during periods ranging between a few seconds to several minutes 1 . On the other end of the spectrum shear stress in arterioles can reach $100 \mathrm{dynes} / \mathrm{cm}^{2} 2$. The impact of shear stress on different biological processes has been clearly demonstrated as for instance during the interaction of leukocytes with the endothelium ${ }^{3}$. To take into account this mechanical parameter in the process of bacterial adhesion we took advantage of an experimental procedure based on the use of a disposable flow chamber ${ }^{4}$. Host cells are grown in the flow chamber and fluorescent bacteria are introduced in the flow controlled by a syringe pump. We initially focused our investigations on the bacterial pathogen Neisseria meningitidis, a Gram-negative bacterium responsible for septicemia and meningitis. The procedure described here allowed us to study the impact of shear stress on the ability of the bacteria to: adhere to cells ${ }^{1}$, to proliferate on the cell surface ${ }^{5}$ and to detach to colonize new sites ${ }^{6}$ (Figure 1). Complementary technical information can be found in reference 7. Shear stress values presented here were chosen based on our previous experience ${ }^{1}$ and to represent values found in the literature. The protocol should be applicable to a wide range of pathogens with specific adjustments depending on the objectives of the study.

\section{Video Link}

The video component of this article can be found at https://www.jove.com/video/3241/

\section{Protocol}

\section{Human host cell and bacterial culture}

1. Culture HUVECs between passage 1 and 9 at $37^{\circ}$ in a humidified incubator with $5 \%(\mathrm{v} / \mathrm{v}) \mathrm{CO}_{2}$. Passage the cells when they approach $80 \%$ confluence with trypsin/EDTA to provide maintenance cultures on $75 \mathrm{~cm}^{2}$ culture flasks and experimental cultures in disposable flow chambers $(\mu$-Slides $\mathrm{VI})$.

2. Withdraw medium from the flasks to be passaged, wash the cells with $10 \mathrm{ml}$ of PBS, withdraw and replace it with $1.5 \mathrm{ml}$ of trypsin/EDTA. Allow the cells to detach in a cell culture incubator for 5 minutes at $37^{\circ} \mathrm{C}$.

3. Collect the cells with $10 \mathrm{ml}$ of cell culture medium into a $15 \mathrm{ml}$ collection tube. Pellet the cells with a 5 minute centrifugation (at $200 \mathrm{~g}$ ), at room temperature. Suspend the cells in $4 \mathrm{ml}$ of Endo-SFM supplemented with $10 \%(\mathrm{v} / \mathrm{v}) \mathrm{FBS}$ and count them on a Malassez chamber, according to the manufacturer's instructions.

4. Introduce $30 \mu \mathrm{l}$ of a $1 \times 10^{6}$ HUVEC cells per ml suspension into the channel $\left(3 \times 10^{4}\right.$ total) and allow the cells to adhere for 3 hours at $37^{\circ}$ in a humidified incubator with an atmosphere of $5 \%(\mathrm{v} / \mathrm{v}) \mathrm{CO}_{2}$. Add an additional volume of $120 \mu \mathrm{l}$ of Endo-SFM to fill the wells. Cells should form a subconfluent monolayer (Figure 2).

5. Grow N. meningitidis expressing GFP (in this case strain 8013 expressing GFP under the control of an IPTG-inducible promoter), on GCB agar plates containing Kellogg's supplements and $5 \mu \mathrm{g} / \mathrm{ml}$ of chloramphenicol at $37^{\circ} \mathrm{C}$ in a moist atmosphere containing $5 \%(\mathrm{v} / \mathrm{v}) \mathrm{CO}_{2}$ for 16 hours. 


\section{Initial adhesion of individual bacteria to host cells}

1. Adjust the concentration of bacteria grown on GCB agar plates to an OD600 of 0.05 with pre-warmed Endo-SFM containing $10 \%$ ( $\mathrm{v} / \mathrm{v}$ ) FBS and incubate for 120 minutes at $37^{\circ} \mathrm{C}$ in a moist atmosphere containing $5 \%(\mathrm{v} / \mathrm{v}) \mathrm{CO}_{2}$, under gentle shaking (130 rpm). Induce GFP expression by adding $1 \mathrm{mM}$ IPTG into the culture medium for the whole incubation period.

2. Place the disposable $\mu$-Slide on the stage of an inverted microscope equipped with a heated platform to maintain the sample temperature at $37^{\circ} \mathrm{C}$.

3. Pour pre-warmed Endo-SFM supplemented with $2 \%(\mathrm{v} / \mathrm{v})$ FBS into a sterile glass beaker and fill a sterile $50 \mathrm{ml}$ syringe with this medium. Attach the "entry" tubing to the syringe and fill by introducing medium.

4. Connect the "entry" tubing to the $\mu$-Slide, with care, in order to avoid introducing air into the chamber. Then, affix the "exit" tube to the other end and carefully fill the channel with medium to approximately $1 \mathrm{~cm}$ distance from the chamber "exit".

5. Measure the bacterial OD600 and adjust to 0.15 in Endo-SFM containing $2 \%(v / v)$ FBS. In order to look at individual bacteria, any aggregates must be disrupted by vigorous vortexing of the bacterial sample.

6. Place $100 \mu \mathrm{l}$ of Endo-SFM supplemented with $2 \%(\mathrm{v} / \mathrm{v})$ FBS medium into the reservoir and add $100 \mu$ l of the bacterial solution taken from the top of the vortexed solution to avoid sampling any remaining bacterial aggregates.

7. Carefully introduce the $200 \mu \mathrm{l}$ volume into the $\mu$-Slide by turning the stopcock to inject the bacteria into the chamber.

8. Introduce Endo-SFM containing $2 \%(\mathrm{v} / \mathrm{v}) \mathrm{FBS}$, maintained at $37^{\circ} \mathrm{C}$ with the heated platform, into the chamber using a syringe pump with a shear stress compatible with adhesion of 0.044 dynes $/ \mathrm{cm}^{2}$ for 15 minutes.

See for example video 1 or figure 3. After this step, either move to sections 3, 4 or 6.

\section{Quantification of initial adhesion of individual bacteria to host cells}

1. After initial adhesion for 15 minutes, acquire images of ten fields randomly while liquid is still circulating.

2. Analyze the acquired images using the ImageJ software ${ }^{8}$, in order to access the mean number of adherant bacteria per field. This is done as follows: first of all, each image is thresholded using the "Threshold" window found in the "Image" menu to highlight individual adhering fluorescent bacteria, while minimizing the background from the cells. Then, every single bacterium is counted, by using the Plug-In "Cell Counter" (http://rsb.info.nih.gov/ij/plugins/cell-counter.html). The data for each image are reported in an Excel spreadsheet and are averaged to quantify the mean number of adherent bacteria per field.

\section{Measuring the resistance to flow of individual bacteria adherent to host cells}

1. Program the syringe pump set-up to generate shear stress ranging from 3 to 100 dynes $/ \mathrm{cm}^{2}$ for 5 minutes.

2. At the end of the 5 minutes, acquire ten fields randomly chosen as described in step 3.1 , but with the flow stopped prior to the acquisition.

3. Analyze the acquired images as described in step 3.2 and quantify the mean number of remaining bacteria per field.

\section{Measuring the growth of an isolated adherent bacterium to a microcolony}

1. Introduce Endo-SFM containing $10 \%(\mathrm{v} / \mathrm{v}) \mathrm{FBS}$, maintained at $37^{\circ} \mathrm{C}$ with the heated platform, into the chamber using a syringe pump with the chosen shear stress for several hours. Record images for real-time video microscopy at one frame every 5 minutes.

2. Following video microscopy, stop the shear stress by turning off the syringe pump, acquire 2-3 additional images and then stop the image acquisition sequence on the software. An example of bacterial proliferation can be seen on video 2 .

\section{Measuring the resistance to flow of adherent bacterial microcolonies}

1. After the formation of large microcolonies on the cellular surface (step5.2) acquire 2-3 images of both cells (by phase contrast) and bacteria (by GFP-fluorescence) before flow application. For the rest of the experiment, the acquisition protocol will monitor only the fluorescence.

2. Applying high shear stress for 5 minutes $\left(3-100\right.$ dynes $\left./ \mathrm{cm}^{2}\right)$ and record images at one frame every 5 seconds.

3. Stop the shear stress by turning off the syringe pump, acquire 2-3 additional images and then stop the image acquisition sequence on the software.

4. Next, remove the "exit" tubing first and carefully, to avoid emptying the channel and then add pre-warmed fresh medium to fill the wells before removing the "entry" tubing.

5. To quantitatively determine the effect of shear stress on bacterial resistance, a plating assay can be performed as follows: collect the remaining medium and wash the $\mu$-Slide twice with $120 \mu \mathrm{l}$ of PBS, which removes the remaining medium from the channel (both washes are also collected).

6. Detach the infected cells with the addition of $50 \mu \mathrm{l}$ of trypsin/EDTA for 5 minutes at $37^{\circ}$ and mix this detached sample with the suspension collected in the previous step.

7. Perform serial dilutions in PBS and plate a $10 \mu \mathrm{l}$ fraction onto GCB agar plates, in triplicate, in order to determine the number of colony forming units (CFU) on the next day, after incubation of the plates at $37^{\circ} \mathrm{C}$ in an incubator with $5 \%(\mathrm{v} / \mathrm{v}) \mathrm{CO}_{2}$.

Videos 3 and 4 compare the wild type strain with the pilV mutant.

\section{Bacterial detachment from microcolonies}

1. Infect cells in the flow chamber by repeating steps 2.1 to 2.8 and allow the infection to proceed for 30 minutes.

2. Remove unbound bacteria by increasing flow to $10 \mathrm{dynes} / \mathrm{cm}^{2}$ for a period of 2 minutes and allow infection to continue for $2 \mathrm{~h}$. 
3. Reduce flow to 0.15 dynes $/ \mathrm{cm}^{2}$.

4. Every hour, collect a drop of medium coming out of the flow chamber.

5. Perform serial dilutions of the samples and plate them on GCB agar plates.

6. Determine the number of colony forming units (CFU) on the next day, after incubation of the plates at $37^{\circ} \mathrm{C}$ in an incubator with $5 \%(\mathrm{v} / \mathrm{v}) \mathrm{CO}_{2}$.

\section{Representative results}

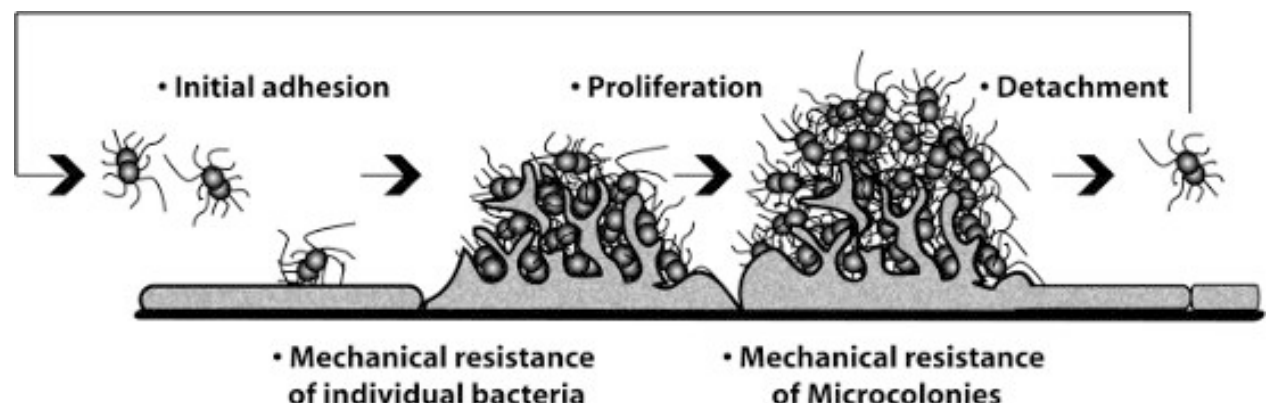

Figure 1: Different steps of a cellular monolayer that can be observed and measured in the presence of flow in the procedure.

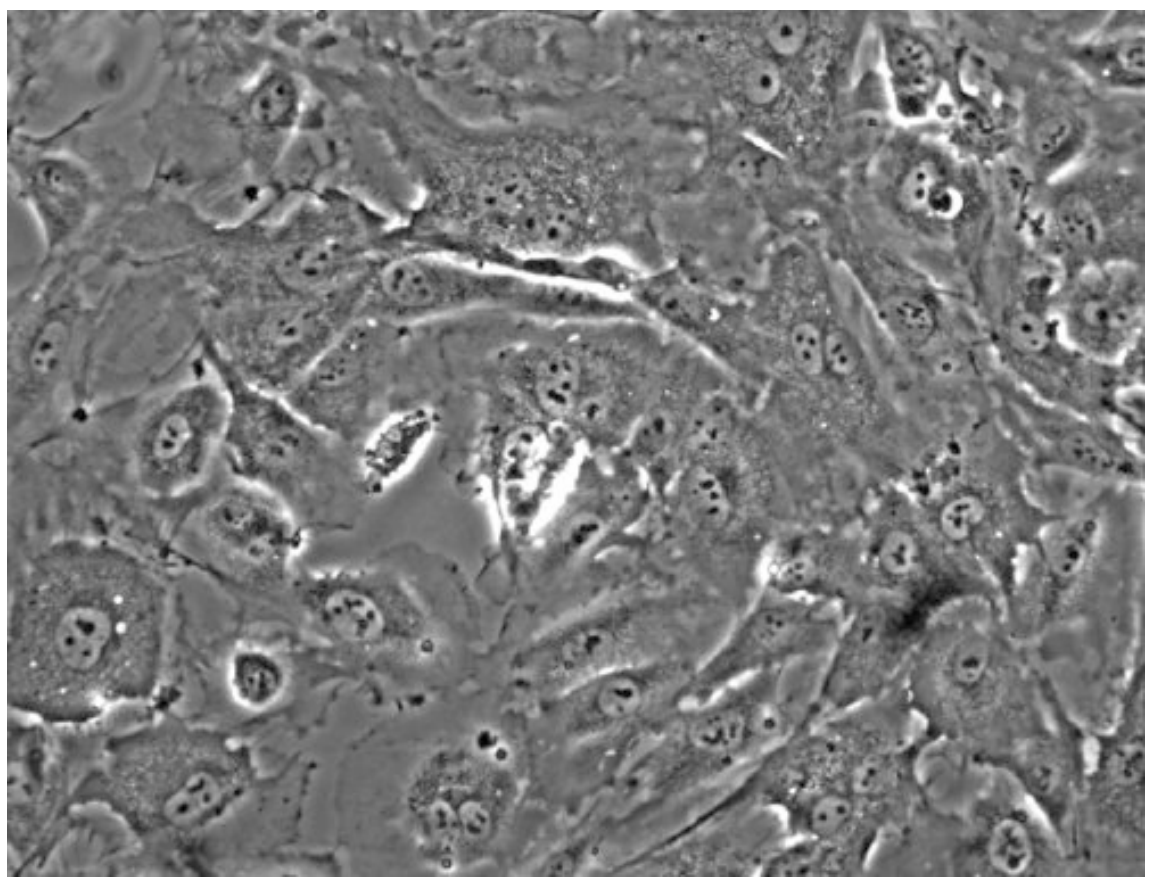

Figure 2: Endothelial cell monolayer in the flow chamber at the beginning of an experiment (absence of shear stress). About 50 endothelial cells are organized in a sub-confluent monolayer. 


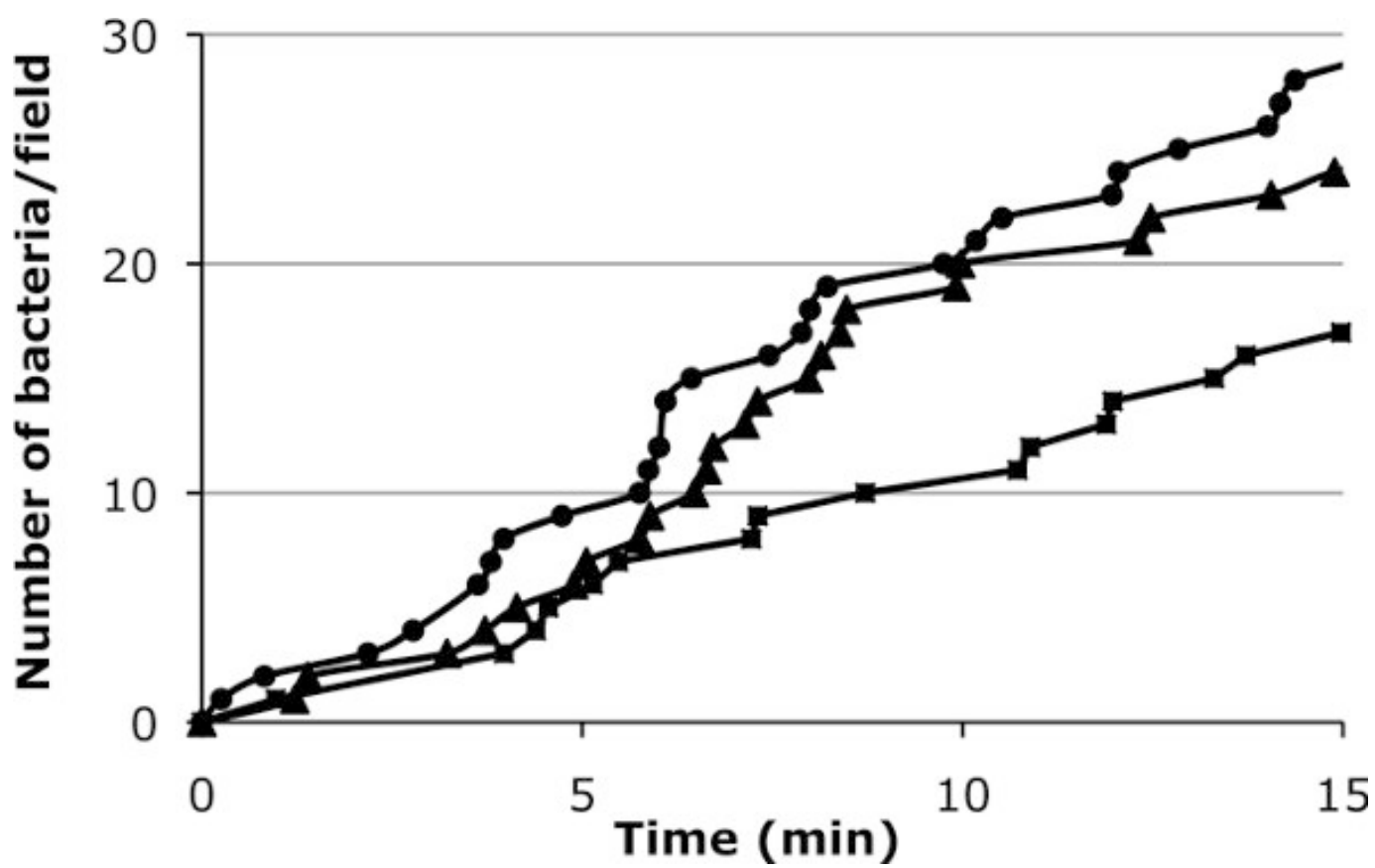

Figure 3: Graphic representation of initial adhesion of bacteria on the cellular surface. Values for three fields are indicated to give an idea of the field-to-field variation that is expected $\left(0,044\right.$ dynes $\left./ \mathrm{cm}^{2}\right)$.

Video 1. Visualization of initial adhesion of bacteria on the cellular monolayer as a function of time $\left(0,044 \mathrm{dynes} / \mathrm{cm}^{2}\right)$. GFP-expressing bacteria are following the direction of the flowing medium. The film is accelerated 60 -fold, the real duration of the video is 10 minutes.

Click here to watch the video.

Video 2. After initial adhesion bacteria were allowed to proliferate on the cellular surface for a period of 7 hours (accelerated 1000-fold).

Click here to watch the video.

Video 3. After Proliferation on the cellular surface the mechanical resistance of microcolonies was tested by increasing the shear stress level to 10 dynes $/ \mathrm{cm}^{2}$ for 5 minutes but wild type microcolonies are resistant accelerated 60 -fold.

Click here to watch the video.

Video 4. Microcolonies formed by the pilV mutant are disrupted by flow increase $\left(10 \mathrm{dynes} / \mathrm{cm}^{2}\right)$. This mutant fails to induce the remodeling of the plasma membrane under microcolonies and is thus more highly sensitive to increased shear stress (video is accelerated 60-fold) ${ }^{5}$. Click here to watch the video.

\section{Discussion}

The importance of shear stress and generally of mechanical aspects in biology is increasingly being recognized. For instance the highly adapted adhesive properties of the Selectin family of proteins in the process of lymphocytes adhesion and rolling on the vascular wall has been recognized by introducing shear stress in the process. The procedure described above was applied to the Gram-negative bacteria Neisseria meningitidis but should be applicable to a wide range of pathogens. The importance of shear stress has been shown also for other pathogens and other infection sites. Bacterial adhesion conditioned by shear stress has been described by the study of the FimH adhesin found on uropathogenic Escherichia coli (UPEC) ${ }^{9}$. Similar to Selectins, the interaction between FimH and its host cell receptor was shown to be strengthened by shear-induced mechanical forces ${ }^{9}$ and the $\mathrm{CfaE}$ adhesin of enterotoxigenic E.coli has been reported also to mediate adhesion to intestinal epithelial cells via a shear-dependant mechanism ${ }^{10}$. We reported, using the laminar-flow chamber assay protocol described in this chapter that Streptococcus agalactiae pili were essential for adherence of this pathogen to epithelial cells under flow conditions ${ }^{11}$. Such studies confirm that our flow chamber assay is a useful tool for investigating host cell-pathogen interactions under conditions of shear stress.

\section{Disclosures}

No conflicts of interest declared.

\section{Acknowledgements}

The authors would like to thank Emilie Mairey and Emmanuel Donnadieu for the initial setting up of the procedure. 


\section{References}

1. Mairey, E., et al. Cerebral microcirculation shear stress levels determine Neisseria meningitidis attachment sites along the blood-brain barrier. J Exp Med. 203, 1939-1950 doi: jem.20060482 [pii] 10.1084/jem.20060482 (2006).

2. Pries, A.R., Secomb, T.W., \& Gaehtgens, P. Design Principles of Vascular Beds. Circ Res. 77, 1017-1023 (1995).

3. Zarbock, A. \& Ley, K. Neutrophil adhesion and activation under flow. Microcirculation. 16, 31-42 doi:906058478 [pii] 10.1080/10739680802350104 (2009).

4. Tissot, O., Pierres, A., Foa, C., Delaage, M. \& Bongrand, P. Motion of cells sedimenting on a solid surface in a laminar shear flow. Biophys J. 61, 204-215 doi:S0006-3495(92)81827-1 [pii] 10.1016/S0006-3495(92)81827-1 (1992).

5. Mikaty, G., et al. Extracellular bacterial pathogen induces host cell surface reorganization to resist shear stress. PLoS Pathog. 5, e1000314 (2009).

6. Chamot-Rooke, J., et al. Posttranslational modification of pili upon cell contact triggers N. meningitidis dissemination. Science. 331, 778-782 doi:331/6018/778 [pii] 10.1126/science.1200729 (2011).

7. Soyer, M. \& Duménil, G. Bacterial adhesion under shear stress, In Neisseria meningitidis: Methods and Protocols (Christodoulides, M., Ed.), Methods in Molecular Biology. Humana Press Inc., New York. (In press, 2011).

8. Abramoff, M.D., Magelhaes, P.J., \& Ram, S.J. Image Processing with ImageJ. Biophotonics International. 11, 36-42 (2004).

9. Thomas, W.E., Trintchina, E., Forero, M., Vogel, V., \& Sokurenko, E.V. Bacterial adhesion to target cells enhanced by shear force. Cell. 109, 913-923 doi:S0092867402007961 [pii] (2002).

10. Tchesnokova, V., et al. Shear-enhanced binding of intestinal colonization factor antigen I of enterotoxigenic Escherichia coli. Mol Microbiol. 76, 489-502 doi:MMI7116 [pii] 10.1111/j.1365-2958.2010.07116.x (2010).

11. Konto-Ghiorghi, Y., et al. Dual role for pilus in adherence to epithelial cells and biofilm formation in Streptococcus agalactiae. PLoS Pathog $\mathbf{5}$, e1000422 (2009). 